\title{
Effects of a healthy meal course on spontaneous energy intake, satiety and palatability
}

\author{
Peter C. Poortvliet ${ }^{1}$, Sonia Bérubé-Parent ${ }^{1}$, Vicky Drapeau ${ }^{1}$, Benoit Lamarche ${ }^{2}$, \\ John E. Blundell ${ }^{3}$ and Angelo Tremblay ${ }^{1,2 *}$ \\ ${ }^{1}$ Division of Kinesiology, Department of Social and Preventive Medicine, Laval University, Sainte-Foy, Quebec, Canada \\ ${ }^{2}$ Institute of Nutraceuticals and Functional Foods, Laval University, Sainte-Foy, Quebec, Canada \\ ${ }^{3}$ Psychobiology Group, Institute of Psychology and Sciences, University of Leeds, Leeds, UK
}

(Received 7 February 2006 - Revised 9 October 2006 - Accepted 10 October 2006)

\begin{abstract}
Many food components can influence satiety or energy intake. Combined together, these food components could represent an interesting dietary strategy in the prevention and treatment of obesity. The aims of this study were: 1) to determine the effect of a functional food in the form of a healthy meal course on subsequent energy intake and satiety; 2) to verify if it is possible to maintain palatability while preserving the satiating effects of the test meal. Thirteen subjects were invited to eat two lunch sessions: healthy and control meal courses (2090 kJ/meal). Anthropometric and ad libitum food intake measurements, and visual analogue scales (VAS) were performed during the two lunch sessions. The healthy main course acutely decreased energy intake during the rest of the meal $(-744 \mathrm{~kJ}, P \leq 0.0001)$ and lipid $(-6 \%, P \leq 0.0001)$ compared with the control meal. VAS ratings during the course of the testing showed a meal effect for hunger, desire to eat and prospective food consumption $(P \leq 0.05)$ and a time effect for all appetite sensations $(P \leq 0 \cdot 0001)$. VAS scores on hunger ratings were lower for the healthy meal $(P \leq 0 \cdot 05)$, whereas fullness ratings were higher shortly after the healthy main course $(P \leq 0.05)$. The healthy meal produced a slightly higher palatability rating but this effect was not statistically significant. These results suggest that it is possible to design a healthy meal that decreases spontaneous energy intake and hunger without compromising palatability.
\end{abstract}

Appetite control: Palatability: Energy intake: Macronutrients: Functional food

The obesity epidemic that is prevailing in most countries of the world is imposing a significant pressure towards the search for solutions that can induce a spontaneous negative energy balance. In the field of nutrition, energy restriction of different degrees of severity has been traditionally used to produce this effect. Unfortunately, clinical research and experience have not proven the efficacy of this approach since weight loss is generally a short-term achievement and weight regain is usually observed over time (Wadden et al. 1989; Anderson et al. 2001). This suboptimal outcome is troublesome for health professionals, particularly dietitians, who have taken advantage in some cases of this reality to become more sensibilized to the idea that an energy deficit induced by diet management cannot be dissociated from the potential of food to promote satiety. In this regard, numerous studies have identified some nutrients and food ingredients that can produce a short-term increase in satiety and/or a spontaneous decrease in energy intake. This literature suggests that a highly satiating food should tend to be characterized by a low lipid content (Lissner et al. 1987; Tremblay et al. 1989, 1991), a minimal alcohol content (Tremblay et al. 1995; Tremblay \& St-Pierre, 1996), a preference for low glycaemic index carbohydrates (Ludwig, 2000; Roberts, 2003; Warren et al. 2003), a high protein content (Skov et al.
1999; Eisenstein et al. 2002), a high dietary fibre content (Howarth et al. 2001; Pereira \& Ludwig, 2001; Koh-Banerjee \& Rimm, 2003), a low energy density (Stubbs et al. 1995; Bell et al. 1998; Rolls et al. 1999a, 2005), a large food volume (Rolls et al. 1998, 1999b), an adequate level of vitamins and minerals (Doucet et al. 2000; Johnston, 2005), particularly Ca (Zemel et al. 2000; Jacqmain et al. 2003), and the content of some thermogenic and/or anorectic compounds such as caffeine (Poehlman et al. 1985; Tremblay et al. 1988; Dulloo et al. 1989), capsaicin (Yoshioka et al. 2001), Oolong tea (antioxidants) (Rumpler et al. 2001) and green tea catechins (Dulloo et al. 1999; Berube-Parent et al. 2005; Diepvens et al. 2005; Westerterp-Plantenga et al. 2005). This literature suggests that a highly satiating food that integrates these nutritional properties in one single meal could favour, in an ad libitum context, a negative energy balance. This represents a major challenge for the food industry since the development of such meal/menus must reconcile a high palatability level with highly satiating components. This is also an important point since investigations have demonstrated that organoleptic and sensory properties of food tend to significantly alter feeding behaviours and spontaneous energy intake (Drewnowski, 1995; Sorensen et al. 2003; Rolls, 2005).

\footnotetext{
Abbreviations: VAS, visual analogue scale.

*Corresponding author: Dr Angelo Tremblay, fax +1 418656 3044, email angelo.tremblay@kin.msp.ulaval.ca
} 
The integration of all these observations emphasizes the relevance of a further step of research that would be closer to the needs of patients subjected to a weight-loss programme. In such a context, the main issue is not the standardization for any single factor potentially influencing energy intake but is rather the testing of palatable menus/meals integrating many satiating food properties to induce a maximal impact on energy intake under conditions that are as representative as possible of free-living conditions. Moreover, it is important to design highly palatable menus aimed at facilitating the spontaneous compliance to a diet of reduced energy content. Therefore, the first aim of this study was to determine the effects of a functional food characterized by healthy and satiating attributes (also referred to as healthy meal course) on subsequent energy intake and satiety for the rest of the meal (dessert) and on total daily energy intake compared with a control main meal course. A second aim of this study was to evaluate the palatability of this healthy meal course as well as to determine the amount of money that subjects would be ready to pay for it.

\section{Subjects and methods}

\section{Subjects}

Fifteen healthy men volunteered to participate in the present study but two of them were excluded because of their noncompliance to study procedures. The remaining thirteen men were aged 26 (SD 4) years and the main relevant anthropometric characteristics were as follows: body weight 73.2 (SD 8.0) $\mathrm{kg}$; height 1.76 (SD 0.06) m; BMI 23.9 (SD 2.1) kg/m². All subjects were non-smokers, did not have any special dietary requirements (e.g. vegetarian), did not take any medication, had a sedentary lifestyle or were moderately physically active (i.e. less than $3 \mathrm{~h}$ physical exercise per week) and maintained a stable body weight over the last 3 months preceding the study $( \pm 4 \mathrm{~kg})$. In addition, subjects had no previous knowledge of the concept of healthy meal impact on satiety, were not allergic to, nor did they have an aversion to, any of the food ingredients used in the present study. The protocol was approved by the Laval University Ethics Committee and written informed consent was obtained from all subjects.

\section{Testing procedures}

The protocol was based on a within subjects, repeated measures design. The subjects were invited to the laboratory on two randomly assigned occasions, separated by a 1-week period, for a 1-h session, during which they were offered a two-course lunch test. Before this session, the subjects had instructions to consume a standardized breakfast at home $4 \mathrm{~h}$ before the lunch test. This breakfast was provided by the research team and consisted of white bread, butter, peanut butter, cheddar cheese and an orange. Its energy content was $3066 \mathrm{~kJ}$ (44, 42 and $14 \%$ from carbohydrate, fat and protein, respectively). Until arrival at the laboratory, subjects were instructed not to eat or drink anything except water if necessary.

After the anthropometric measurements were performed, compliance to the standardized breakfast was verified. The subjects also completed a four-question visual analogue scale (VAS) (Hill \& Blundell, 1986) to obtain ratings on a $150 \mathrm{~mm}$ scale for hunger, desire to eat, fullness and prospective food consumption (quantity of food that the participants thought they could eat) as well as food appreciation after the meal. The main course (healthy meal or control) of the lunch was then served and had to be entirely consumed within a 30-min period. Immediately after finishing this course, VAS on appetite sensations and the appreciation of the meal were completed. A questionnaire on general features of the meal, the willingness to buy the food at a grocery, the amount of money to be ready to be paid for a similar meal and other comments was also completed (Appendix 1). Approximately $10 \mathrm{~min}$ after finishing the first course, the subjects were offered a dessert (second course) that they could eat ad libitum within a 15 -min period. Just before serving the dessert, VAS on appetite sensations were completed. Upon finishing the dessert, subjects again completed VAS on appetite sensations and appreciation of the dessert. After the lunch, subjects were instructed not to eat during the next $3 \mathrm{~h}$, during which they had to complete VAS on appetite sensations every $30 \mathrm{~min}$.

Thereafter, they were free to eat but they had to complete a dietary record to evaluate food and energy intake for the remainder of the day. To ensure a realistic approximation of the energy consumed, subjects were instructed to be as precise as possible by indicating the source, quantities, place of consumption (out or at home) and consumption time. After completion, a nutritionist revised each record with each subject to validate the information obtained with the dietary record.

Each food, including water, served during each course of the meal was weighed before and after consumption with a food scale (Weigh Tronix, VI-4000, Acculab) at the nearest $0 \cdot 1 \mathrm{~g}$ to determine energy and macronutrient intakes as well as the weight of food consumed. Total daily energy intake was calculated by summing the energy content of breakfast, the measured intake at lunch time and the reported intake for the rest of the day. The calculation of energy and macronutrient content of the food (measured and reported) was performed using the Canadian Nutrient File (Health and Welfare Canada, 1997).

\section{Two lunch sessions: healthy and control main courses}

The two lunch sessions tested included two courses each, i.e. main and dessert. The first course was a main course with a standardized energy content characterized by different satiating, organoleptic and sensory properties (healthy or control main course). The second one consisted of a dessert that was served ad libitum. The dessert was provided by a caterer and consisted

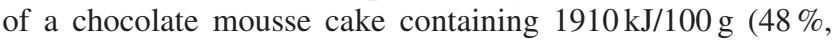
$44 \%$ and $8 \%$ from carbohydrate, lipid and protein, respectively). In other words, the main course was the only part of the meal that differed between the two lunch sessions.

The satiating ingredients combined in the healthy meal course were selected based on their known individual impact on short-term satiety and/or energy intake (see p. 584 for references). Accordingly, the healthy meal course was designed with a reduced fat content, an increased protein and fibre content, a lower energy density, the addition of some spicy ingredients, such as capsaicin, and with a higher volume. The list of ingredients, the nutritional content, the 
price of the two main courses, i.e. chicken stir-fry and fettuccini carbonara, are presented in Table 1 . The chicken stir-fry main course was specially designed in order to increase satiety (healthy main course) whereas the fettuccini carbonara course was considered as a usual reference dish (control main course).

\section{Anthropometric measurements}

Body weight and height were measured to the nearest $0.1 \mathrm{~kg}$ and $0.1 \mathrm{~cm}$, respectively. BMI was calculated as body weight divided by height squared $\left(\mathrm{kg} / \mathrm{m}^{2}\right)$. Furthermore, waist circumference was measured to $0.1 \mathrm{~cm}$ accuracy using a Gulick fibreglass anthropometric tape (M-22C; Creative Health Products, Ann Arbor, MI, USA).

\section{Statistical analysis}

Data were analysed by using SAS-PC for Windows (version 9.1; SAS Institute, Cary, NC, USA) and expressed as means and standard deviations. Statistical significance was set at $P<0 \cdot 05$. Food intake $(\mathrm{g})$, energy intake $(\mathrm{kJ})$ and the percentage of macronutrients were analysed for the standardized breakfast, the two courses (main and dessert) of the lunch and the rest of the day following the lunch. These variables and total daily intake were compared between the two lunch sessions by using a paired $t$ test. VAS ratings during the course of the session were analysed by using a two-way ANOVA for repeated measures in order to test time, meal and time $\times$ meal interaction effects. Thereafter, a paired $t$ test was used to analyse the different VAS ratings.

\section{Results}

\section{Energy and macronutrient intakes}

Mean energy intake at different times over the day for both lunch sessions is presented in Table 2. Energy intake was significantly lower $(-744$ (SD 635) $\mathrm{kJ}, P \leq 0 \cdot 001)$ after the lunch dessert (second course) with the healthy main course (chicken stir-fry) compared with the control main course (fettuccini carbonara). Since the main course of each meal had a similar energy content, this difference also represented the decrease in energy intake for the whole meal at lunch in the satiating condition. When comparing energy intakes from the food records, subjects also tended to consume less energy after the healthy satiating lunch session than in the control lunch session but this difference was not statistically significant $(-1028$ (SD 2943) kJ, $P>0.05)$. Total daily intake also tended to be lower for the chicken stir-fry lunch session compared with the control lunch session ( -1756 (SD 3064) kJ, $P=0 \cdot 067)$.

Table 1. Pictures, lists of ingredients, nutritional values and costs of the healthy meal (chicken stir-fry) and the control meal (fettuccini carbonara) courses

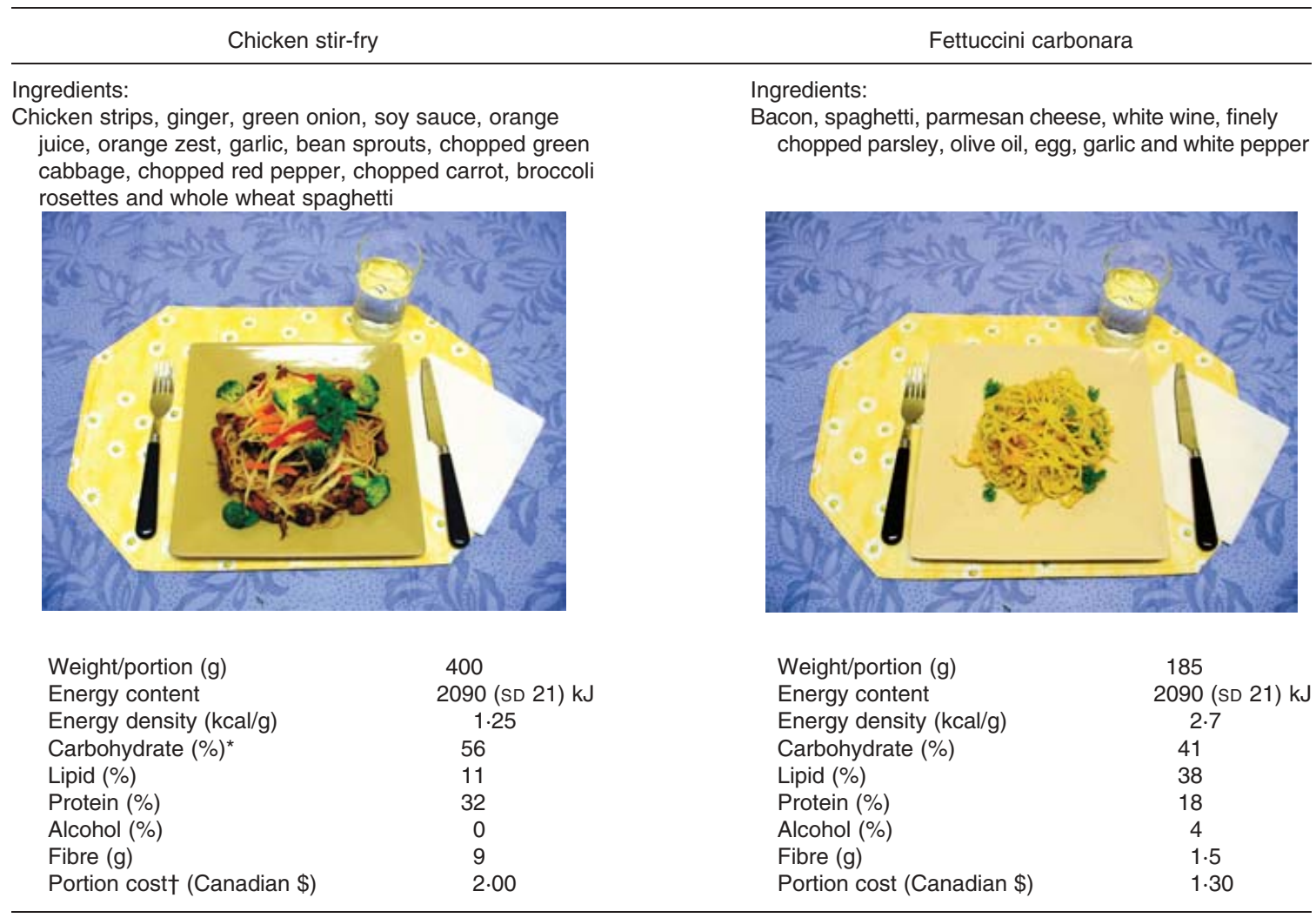

* Percentage of energy intake.

†Prices were based on seasonal availability of the ingredients used.

For details of subjects and procedures, see pp. 585-586. 
Table 2. Energy intakes during the two lunch sessions $\ddagger$ (Mean values and standard deviations)

\begin{tabular}{|c|c|c|c|c|}
\hline \multirow[b]{2}{*}{ Variables } & \multicolumn{2}{|c|}{$\begin{array}{l}\text { Healthy meal: } \\
\text { chicken stir-fry }\end{array}$} & \multicolumn{2}{|c|}{$\begin{array}{l}\text { Control meal: } \\
\text { fettuccini carbonara }\end{array}$} \\
\hline & Mean & SD & Mean & SD \\
\hline \multicolumn{5}{|c|}{ Lunch dessert (second course) } \\
\hline Energy (kJ) & 2362 & 1342 & $3106^{\star * \star}$ & 1434 \\
\hline $\begin{array}{l}\text { Amount of food } \\
\text { consumed }(\mathrm{g})\end{array}$ & 124 & 70 & $163^{\star \star \star}$ & 75 \\
\hline Water $(\mathrm{g})$ & 154 & 131 & 210 & 123 \\
\hline Carbohydrate (\%) & 48 & & 48 & \\
\hline Lipid (\%) & 44 & & 44 & \\
\hline Protein (\%) & 8 & & 8 & \\
\hline Alcohol (\%) & - & & - & \\
\hline \multicolumn{5}{|c|}{ Total lunch intake: Main course + dessert } \\
\hline Energy (kJ) & 4427 & 1363 & $5154^{\star *}$ & 1476 \\
\hline $\begin{array}{l}\text { Amount of food } \\
\text { consumed }(\mathrm{g})\end{array}$ & 565 & 75 & $366^{\star \star \star}$ & 79 \\
\hline Carbohydrate (\%) & 52 & 1 & $45^{\star \star \star}$ & 1 \\
\hline Lipid (\%) & 27 & 4 & $42^{\star \star \star}$ & 1 \\
\hline Protein (\%) & 20 & 3 & $12^{\star \star \star}$ & 1 \\
\hline Alcohol (\%) & - & & 1 & 1 \\
\hline \multicolumn{5}{|c|}{ Food record (intake during the rest of the day) } \\
\hline Energy (kJ) & 4932 & 1659 & 5961 & 3804 \\
\hline Carbohydrate (\%) & 48 & 11 & 46 & 13 \\
\hline Lipid (\%) & 31 & 10 & 35 & 9 \\
\hline Protein (\%) & 19 & 8 & 17 & 5 \\
\hline Alcohol (\%) & 3 & 6 & 2 & 5 \\
\hline \multicolumn{5}{|l|}{ Total daily intake } \\
\hline Energy (kJ) & 12394 & 2533 & $14149 \dagger$ & 3833 \\
\hline Carbohydrate (\%) & 48 & 5 & $45^{\star}$ & 7 \\
\hline Lipid (\%) & 33 & 4 & $39^{\star \star *}$ & 4 \\
\hline Protein (\%) & 18 & 3 & $14^{*}$ & 3 \\
\hline Alcohol (\%) & 1 & 2 & 1 & 2 \\
\hline
\end{tabular}

df 12 , mean values were significantly different from those for fettuccini carbonara: ${ }^{\star} P \leq 0.05 ;{ }^{\star \star} P \leq 0.01 ;{ }^{* \star \star} P \leq 0.001 ; \dagger P=0.067$.

$\ddagger \%$ indicates the percentage of energy intake.

For details of diets and procedures, see pp. 585-586.

Total macronutrient intakes were significantly different between the two lunch sessions. After the healthy meal course session, the percentage of energy intake as carbohydrate and protein was significantly higher compared with the control main course $(+3.3(\mathrm{SD} 4.8)$ and $+3 \cdot 2(\mathrm{SD} 4 \cdot 1)$ $\%, P<0.05$, respectively). In contrast, the proportion of energy intake from lipid was significantly lower after the healthy meal course ( -6.1 (SD 3.5) \%,P $\leq 0.0001)$. The differences in total daily macronutrient intake were mainly attributable to the composition of the healthy meal course.

\section{Visual analogue scale ratings}

Subjective ratings for hunger, fullness and prospective food consumption are presented in Fig. 1. Subjective ratings for desire to eat are not presented since they had a similar pattern to VAS ratings for hunger. All VAS ratings were influenced by a significant time effect $(P \leq 0 \cdot 01)$. There was also a significant meal effect for hunger, desire to eat and prospective food consumption $(P \leq 0 \cdot 05)$. However, there was no significant time by meal interaction. There was no significant difference in ratings before each lunch session, which indicates similar baseline lunch sessions. The ratings for hunger and prospective food consumption were significantly lower immediately after the chicken stir-fry main course lunch compared with the control main course $(0 \cdot 001 \leq$ $P \leq 0 \cdot 01$, whereas those for fullness were significantly higher after the healthy meal course $(0.001 \leq P \leq 0.01)$. The ratings for hunger remained significantly lower after the healthy meal course for the duration of the lunch and the three postprandial hours $(P \leq 0 \cdot 05)$. Feelings of fullness did not differ significantly during the same period between the two conditions. Prospective food consumption was significantly lower after the healthy meal course for as long as $30 \mathrm{~min}$ after the lunch $(P \leq 0 \cdot 05)$. After this time, the ratings were still lower but the difference was no longer significant, except for the 150-min rating $(P \leq 0 \cdot 05)$.

\section{Palatability}

The VAS ratings for appreciation of the meal were slightly higher for the chicken stir-fry main course (116 (SD 30) min) immediately after its ingestion compared with the control main course (105 (SD 25) min) but this difference was not statistically significant $(P=0 \cdot 23)$. After the dessert, ratings for appreciation of the meal were again higher for the healthy meal session (113 (SD 27) min) compared with the control course food session (106 (SD 36) min) but this difference was also non-significant $(P=0 \cdot 33)$.

\section{General perception of the meal}

The questionnaire documenting the general perception of the meal indicated that subjects appreciated both meals. The chicken stir-fry meal was appreciated because of the diversity, quality, taste, colour and freshness of the ingredients used. The portion size of this meal was found to be generous in comparison with the portion size of the control meal, which was perceived as undersized. This was concordant with the fact that more time was needed to consume the chicken stirfry compared with the fettuccini carbonara course (difference of 9.31 (SD 1.61) min). Finally, this questionnaire revealed that subjects were willing to pay Canadian \$2.05 (SD 0.38) more for a meal similar to the healthy meal course compared with a meal similar to the control main course.

\section{Discussion}

In accordance with the first law of thermodynamics, the dietary management of obesity over the last decades has been focused on energy-restricted diets aimed at achieving a short-term energy deficit (National Institutes of Health, 1998). Accordingly, it is not surprising that such approaches were found to be successful to induce body-weight loss in the short term in most individuals (Wadden et al. 1989; Wadden, 1993; Anderson et al. 2001). However, when the outcome is examined on a long-term basis, it seems that the initial success gives way to frustration, since weight regain is often the endpoint of the intention to treat obese individuals (Wadden et al. 1989; Anderson et al. 2001). This impels dietitians and food specialists to reconsider the mode of treatment in order to reconcile the maintenance of a negative energy balance state with healthy food practices.

The identification of dietary compounds that can increase satiety and/or decrease spontaneous energy intake have raised optimism regarding the development of healthy satiating foods that might have the potential to improve compliance to a negative energy balance. As discussed earlier, the main 

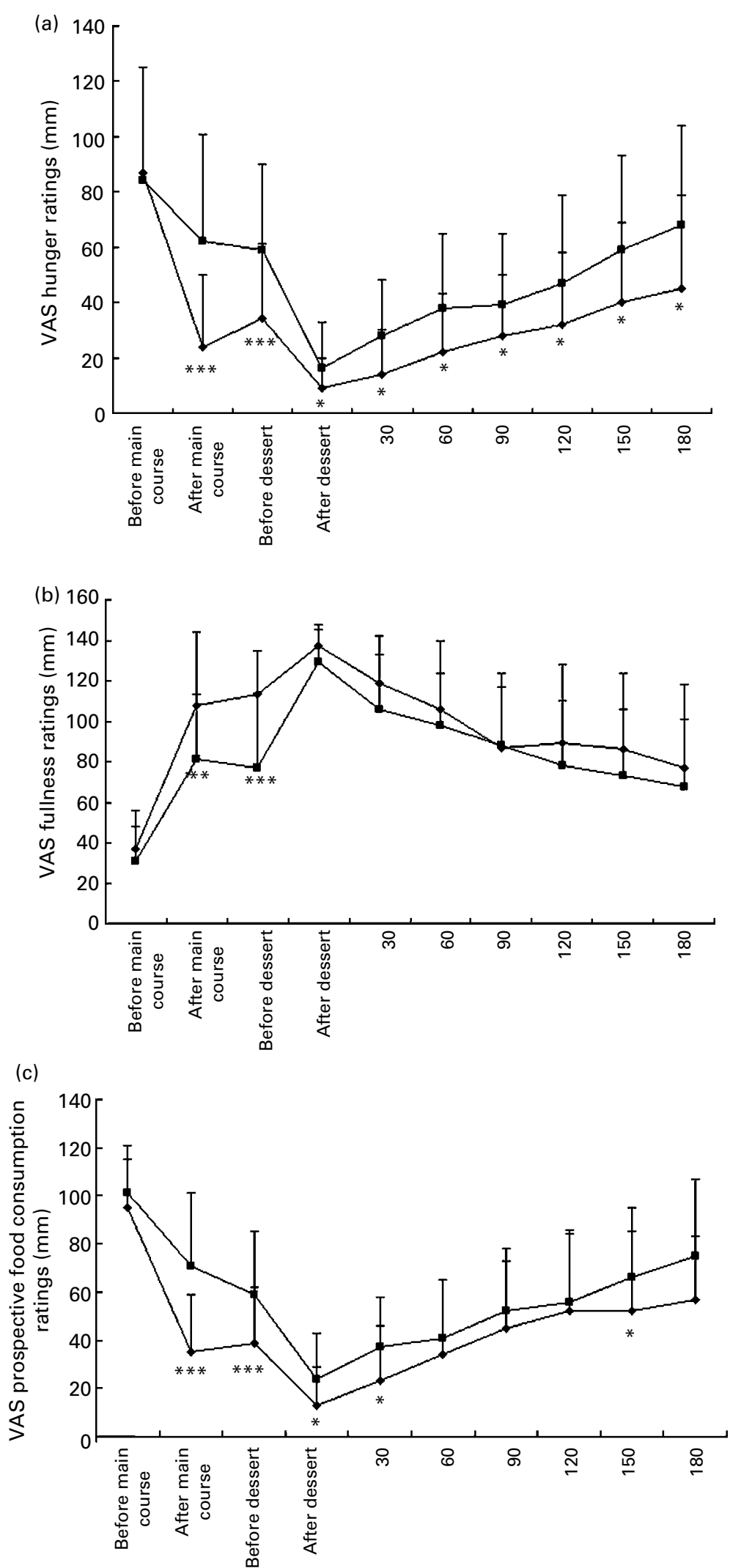

Fig. 1. Visual analogue scale (VAS) ratings for (a) hunger, (b) fullness and (c) prospective food consumption in the two lunch sessions: healthy meal (- -; chicken stir-fry) and control meal (- - - fettuccini carbonara). Values are means and standard deviations, df 12 . Mean values were significantly different from those for fettuccini carbonara: ${ }^{\star} P \leq 0.05 ;{ }^{* \star} P \leq 0.01 ;{ }^{* \star *} P \leq 0.001$. For details of diets and procedures, see pp. 585-586. 
issue thus becomes a food planning strategy that integrates the maximal number of food-related satiating properties to reduce energy intake without the perception of undereating and/or restriction. As a first approach evaluating this issue, we designed menus with the goal of promoting satiety at a fixed energy intake. We also assessed the degree of compatibility between satiety-promoting food and palatability, and the degree of readiness to pay for such a food concept.

In agreement with the previously described food/nutrient properties known to influence appetite control (Drapeau \& Tremblay, 2000), the healthy meal course tested in the present study, i.e. the chicken stir-fry, was characterized by a reduced fat content, an increased protein and fibre content, the addition of capsaicin and a lower energy density and a higher volume compared with the reference control course. Immediately after its ingestion, the levels of perceived feelings of hunger were decreased, which was consistent with the significant subsequent decrease in energy intake at dessert, which was offered ad libitum. Interestingly, the increased state of satiety induced by the chicken stir-fry course was still observed for several hours after lunch time and was associated with an additional decrease in energy intake at dinner time. Taken together, these repeated decreases resulted in a cumulative reduction in energy intake of $1756 \mathrm{~kJ} / \mathrm{d}$. Such a change over two meals is significant and could theoretically represent a body weight loss of about $0 \cdot 5 \mathrm{~kg} /$ week. This corresponds to a typical energy deficit and body-weight loss generally targeted in obesity intervention (National Institutes of Health, 1998).

Because the two meals were different in appearance, smell, texture, taste, water content, volume and that all these factors have been shown to influence energy intake (Rolls et al. 1998; Sorensen et al. 2003), it is difficult to precisely identify which characteristic of the meal caused the expected decrease in spontaneous energy intake. In this regard, the main aim of the present study was not to describe the contribution of each specific feature of the healthy meal course but was rather to design a course integrating these properties in a palatable menu to promote a negative energy balance compared with a standard meal. From a clinical standpoint, this study suggests that, in the short term, a substantial decrease in spontaneous energy intake could be reached with the consumption of healthy menus without any compromise on perceived pleasantness of food. The next step would be to perform a longer study in the obese population with other healthy satiating and control meals to confirm and extend these results.

Since pleasure and satisfaction seem to be important determinants for the adherence to many healthy practices (Esch \& Stefano, 2004), such as healthy food habits, it is clear that food palatability should be viewed as an important criterion to be considered in the design of healthy foods. In the present study, it is encouraging to note that the chicken stir-fry course received an appreciation score that was equal to or slightly higher than the palatable fettuccini carbonara control course. This suggests that it is realistic and feasible to achieve a highly satiating food profile and palatability in a context where a negative energy balance is a desired outcome.

Another important feature of healthy meals, be it in the field of obesity or in regard to other health-related issues, is related to the cost issue (Horgen \& Brownell, 2002). As indicated in Table 1, the cost of the ingredients of the chicken stir-fry exceeded by Canadian $\$ 0.70$ the cost of those included in our fettuccini carbonara recipe. However, the appreciation questionnaire completed by the subjects indicated that they would have paid Canadian $\$ 2.05$ more for the chicken stirfry than for the fettuccini carbonara course. Again, these observations are encouraging since they suggest that industrial food producers might experience success in their endeavour to achieve both profitability and the production of healthy foods.

The results of the present study have shown that a healthy meal course can successfully improve satiety and reduce subsequent energy intake. The current data also suggest that it is possible to take advantage of these properties without compromising short-term appetite control. Finally, the opinion of our subjects indicated a readiness to pay more money for these foods compared with the additional cost of their ingredients.

\section{Acknowledgements}

Peter C. Poortvliet is supported by a studentship from the Vrije Universiteit of Amsterdam and Angelo Tremblay is partly funded by the Canada Research Chair in Physical Activity, Nutrition, and Energy Balance. The authors express their gratitude to the subjects for their excellent collaboration and the staff of the Division of Kinesiology for their contribution to this study.

\section{References}

Anderson JW, Konz EC, Frederich RC \& Wood CL (2001) Longterm weight-loss maintenance: a meta-analysis of US studies. Am $J$ Clin Nutr 74, 579-584.

Bell EA, Castellanos VH, Pelkman CL, Thorwart ML \& Rolls BJ (1998) Energy density of foods affects energy intake in normalweight women. Am J Clin Nutr 67, 412-420.

Berube-Parent S, Pelletier C, Dore J \& Tremblay A (2005) Effects of encapsulated green tea and Guarana extracts containing a mixture of epigallocatechin-3-gallate and caffeine on $24 \mathrm{~h}$ energy expenditure and fat oxidation in men. Br J Nut 94, 432-436.

Diepvens K, Kovacs EM, Nijs IM, Vogels N \& Westerterp-Plantenga MS (2005) Effect of green tea on resting energy expenditure and substrate oxidation during weight loss in overweight females. $\mathrm{Br}$ J Nutr 94, 1026-1034.

Doucet E, Després J-P, Bouchard C \& Tremblay A (2000) Body weight and composition in consumers and non-consumers of vitamin supplements. Int J Obes Relat Metab Disord 24, S157.

Drapeau V \& Tremblay A (2000) Diet and body weight regulation. In Obesity: Pathology and Therapy, pp. 237-258 [D Lockwood and T Heffner, editors]. Berlin Heidelberg: Springer.

Drewnowski A (1995) Energy intake and sensory properties of food. Am J Clin Nutr 62, 1081S-1085S.

Dulloo AG, Duret C, Rohrer D, Girardier L, Mensi N, Fathi M, Chantre P \& Vandermander J (1999) Efficacy of a green tea extract rich in catechin polyphenols and caffeine in increasing 24-h energy expenditure and fat oxidation in humans. Am J Clin Nutr $\mathbf{7 0}$, $1040-1045$.

Dulloo AG, Geissler CA, Horton T, Collins A \& Miller DS (1989) Normal caffeine consumption: influence on thermogenesis and daily energy expenditure in lean and postobese human volunteers. Am J Clin Nutr 49, 44-50.

Eisenstein J, Roberts SB, Dallal G \& Saltzman E (2002) High-protein weight-loss diets: are they safe and do they work? A review of the experimental and epidemiologic data. Nutr Rev 60, 189-200.

Esch T \& Stefano GB (2004) The neurobiology of pleasure, reward processes, addiction and their health implications. Neuro Endocrinol Lett 25, 235-251. 
Health and Welfare Canada (1997) The Canadian Nutrient File, Government of Canada.

Hill AJ \& Blundell JE (1986) The effects of a high-protein or highcarbohydrate meal on subjective motivation to eat and food preferences. Nutrition and Behavior 3, 133-144.

Horgen KB \& Brownell KD (2002) Comparison of price change and health message interventions in promoting healthy food choices. Health Psychol 21, 505-512.

Howarth NC, Saltzman E \& Roberts SB (2001) Dietary fiber and weight regulation. Nutr Rev 59, 129-139.

Jacqmain M, Doucet E, Despres JP, Bouchard C \& Tremblay A (2003) Calcium intake, body composition, and lipoprotein-lipid concentrations in adults. Am J Clin Nutr 77, 1448-1452.

Johnston CS (2005) Strategies for healthy weight loss: from vitamin $\mathrm{C}$ to the glycemic response. J Am Coll Nutr 24, 158-165.

Koh-Banerjee P \& Rimm EB (2003) Whole grain consumption and weight gain: a review of the epidemiological evidence, potential mechanisms and opportunities for future research. Proc Nutr Soc 62, 25-29.

Lissner L, Levitsky DA, Strupp BJ, Kalkwarf HJ \& Roe DA (1987) Dietary fat and regulation of energy intake in human subjects. Am J Clin Nutr 46, 886-892.

Ludwig DS (2000) Dietary glycemic index and obesity. J Nutr 130, 280S-283S.

National Institutes of Health (1998) Clinical guidelines on the identification, evaluation, and treatment of overweight and obesity in adults-The evidence report. Obes Res 6, Suppl. 2, 51S-209S

Pereira MA \& Ludwig DS (2001) Dietary fiber and body-weight regulation. Observations and mechanisms. Pediatr Clin North Am 48, 969-980.

Poehlman ET, Després J-P, Bessette H, Fontaine E, Tremblay A \& Bouchard C (1985) Influence of caffeine on the resting metabolic rate of exercise-trained and inactive subjects. Med Sci Sports Exerc 17, 689-694.

Roberts SB (2003) Glycemic index and satiety. Nutr Clin Care 6, 20-26.

Rolls BJ, Bell EA, Castellanos VH, Chow M, Pelkman CL \& Thorwart ML (1999a) Energy density but not fat content of foods affected energy intake in lean and obese women. Am J Clin Nutr 69, 863-871.

Rolls BJ, Bell EA \& Thorwart ML (1999b) Water incorporated into a food but not served with a food decreases energy intake in lean women. Am J Clin Nutr 70, 448-455.

Rolls BJ, Castellanos VH, Halford JC, Kilara A, Panyam D, Pelkman CL, Smith GP \& Thorwart ML (1998) Volume of food consumed affects satiety in men. Am J Clin Nutr 67, 1170-1177.

Rolls BJ, Roe LS, Beach AM \& Kris-Etherton PM (2005) Provision of foods differing in energy density affects long-term weight loss. Obes Res 13, 1052-1060.

Rolls ET (2005) Taste, olfactory, and food texture processing in the brain, and the control of food intake. Physiol Behav 85, 45-56.

Rumpler W, Seale J, Clevidence B, Judd J, Wiley E, Yamamoto S, Komatsu T, Sawaki T, Ishikura Y \& Hosoda K (2001) Oolong tea increases metabolic rate and fat oxidation in men. $J$ Nutr 131, 2848-2852.

Skov AR, Toubro S, Ronn B, Holm L \& Astrup A (1999) Randomized trial on protein vs carbohydrate in ad libitum fat reduced diet for the treatment of obesity. Int J Obes Relat Metab Disord 23, $528-536$.

Sorensen LB, Moller P, Flint A, Martens M \& Raben A (2003) Effect of sensory perception of foods on appetite and food intake: a review of studies on humans. Int J Obes Relat Metab Disord 27, $1152-1166$.

Stubbs JR, Harbon GH, Murgatroyd PR \& Prentice AM (1995) Covert manipulation of dietary fat and energy density: effect on substrate flux and food intake in men eating ad libitum. Am $J$ Clin Nutr 62, 316-329.

Tremblay A, Lavallée N, Alméras N, Allard L, Després JP \& Bouchard C (1991) Nutritional determinants of the increase in energy intake associated with a high fat diet. Am J Clin Nutr 53, 1134-1137.

Tremblay A, Masson E, Leduc S, Houde A \& Després J-P (1988) Caffeine reduces spontaneous energy intake in men but not in women. Nutr Res 8, 553-558.

Tremblay A, Plourde G, Després JP \& Bouchard C (1989) Impact of dietary fat content and fat oxidation on energy intake in humans. Am J Clin Nutr 49, 799-805.

Tremblay A \& St-Pierre S (1996) The hyperphagic effect of high-fat and alcohol persists after control for energy density. Am J Clin Nutr 63, 479-482.

Tremblay A, Wouters E, Wenker M, St-Pierre S, Bouchard C \& Després J-P (1995) Alcohol and high-fat diet: a combination favoring overfeeding. Am J Clin Nutr 62, 639-644.

Wadden TA (1993) Treatment of obesity by moderate and severe caloric restriction. Results of clinical research trials. Ann Intern Med 119, 688-693.

Wadden TA, Sternberg JA, Letizia KA, Stunkard AJ \& Foster GA (1989) Treatment of obesity by very low calorie diet, behavior therapy, and their combination: a five year perspective. Int $J$ Obes Relat Metab Disord 13, 39-46.

Warren JM, Henry CJ \& Simonite V (2003) Low glycemic index breakfasts and reduced food intake in preadolescent children. Pediatrics 112, e414.

Westerterp-Plantenga MS, Lejeune MP \& Kovacs EM (2005) Body weight loss and weight maintenance in relation to habitual caffeine intake and green tea supplementation. Obes Res 13, 1195-1204.

Yoshioka M, Doucet E, Drapeau V, Dionne I \& Tremblay A (2001) Combined effects of red pepper and caffeine consumption on $24 \mathrm{~h}$ energy balance in subjects given free access to foods. Br J Nutr $\mathbf{8 5}$, 203-211.

Zemel MB, Shi H, Greer B, Dirienzo D \& Zemel PC (2000) Regulation of adiposity by dietary calcium. FASEB $J \mathbf{1 4}, 1132-1138$.

\section{Appendix 1}

Questionnaire reflecting appreciation of the meal, willingness to buy at a grocery and amount of money subjects were willing to pay for a similar meal and other comments.

1. Avez-vous aimé ce plat? OUI/NON

(Did you like this meal? YES/NO)

2. Pourquoi?

(Why?)

3. Acheteriez-vous ce produit à l'épicerie? OUI/NON

(Would you consider buying this product at a grocery? YES/NO)

4. Combien payeriez-vous pour ce produit? Canadiens \$)

(How much would you be willing to pay for a product like this? Canadian \$

5. Autres commentaires appréciés s.v.p.

(Other comments please) 